\title{
THE FREQUENCY OF TUMOUR-LIKE FORMATIONS IN BRONCHIECTATIC LUNGS
}

\author{
BY \\ G. J. CUNNINGHAM, E. NASSAU, AND J. B. WALTER \\ From the Royal College of Surgeons of England and Harefield Hospital, Middlesex
}

(RECEIVED FOR PUBLICATION NOVEMBER 26, 1957)

The occurrence of abnormal clumps of epithelial cells in fibrotic lesions of the lung has been long recognized. Pagel (1926) reviewed the earlier references and gave the first adequate description of these lesions in bronchiectasis. He considered that they were metaplastic rather than neoplastic in nature and related to the bronchiectasis. In contrast, Bert and Fischer (1910) regarded the cells in their case as having their origin in an embryonic rest. Since then, however, the interpretation of their significance has varied considerably. They have been regarded as either atypical hyperplasias, adenomata, carcinoids, or carcinomata. Those writers who have thought them malignant have regarded them as evidence for the peripheral origin of lung cancer. The subject has been well reviewed by Whitwell (1955), who considered that these tumour-like formations or "tumourlets" were hyperplasias rather than true tumours. The majority of earlier reports were based on lesions found in post-mortem material: more recent papers have dealt with their occurrence in bronchiectatic lung tissue removed surgically. Many of these lesions have been found accidentally, and most authors would agree with Cureton and Hill (1955) in saying that they were infrequently found in bronchiectasis.

We have attempted to discover the true frequency of these lesions by a systematic search in bronchiectatic lungs, and the present paper reports the findings in a series of 102 cases.

\section{MATERIAL AND METHOdS}

The material consisted of 102 surgically resected specimens of bronchiectatic lungs. The specimens did not form a consecutive series and were in no way selected. Each specimen was examined without prior knowledge of age or sex, and was inflated with formol saline and sectioned by serial slices in a parasagittal plane. Small blocks were taken from fibrotic or consolidated areas. Between three and 18 blocks were taken from each specimen with an average of 7.4. In some cases one or more large sections were prepared, and these numbered 19.
The type of lesion to which we shall refer as $\overrightarrow{\alpha a}$ "tumourlet" has been well described previously by Whitwell (1955). A common type is composed \&f discrete groups of cells showing small, dark-staining nuclei and pale cytoplasm (Fig. 1). Nucleoli aze absent and mitoses rarely seen. Cells may be seci lying in clefts or spaces giving an appearance similå to that of lymphatic permeation by carcinoma celfs (Fig. 2). In some cases tumourlet cells are fourd lying free in the alveolar spaces (Fig. 3). The origin of the lesions from bronchiolar epithelium may be evident (Fig. 4). Where tumourlets were found a the available lymph nodes were sectioned, and, in a $\overline{8}$ 52 nodes were examined from 16 cases. In the remaining four positive cases, no lymph nodes weri present in the specimen.

\section{RESULTS}

The results are shown in Fig. 5 and Table Out of a total of 102 cases, 20 were found $t \overline{8}$ have tumourlets. Of those patients aged 20 year

TABLE I

ANALYSIS OF 20 "TUMOURLET" CASES SHOWING AGE SEX, AND NUMBER AND SIZE OF LESIONS

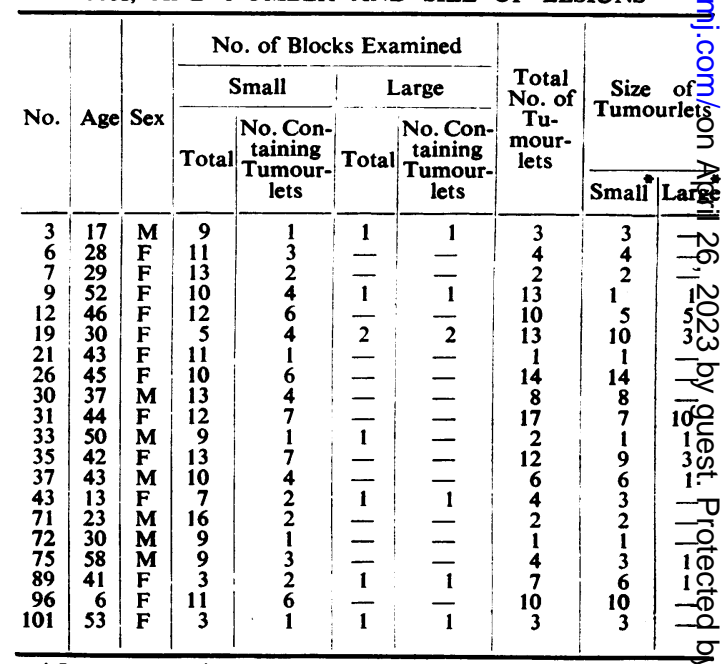

* Large tumourlets were those occupying one low-power field 8 more, using 23 in. objective and $\times 8$ eyepieces. Small tumourlos occupied less than one low-power field. 


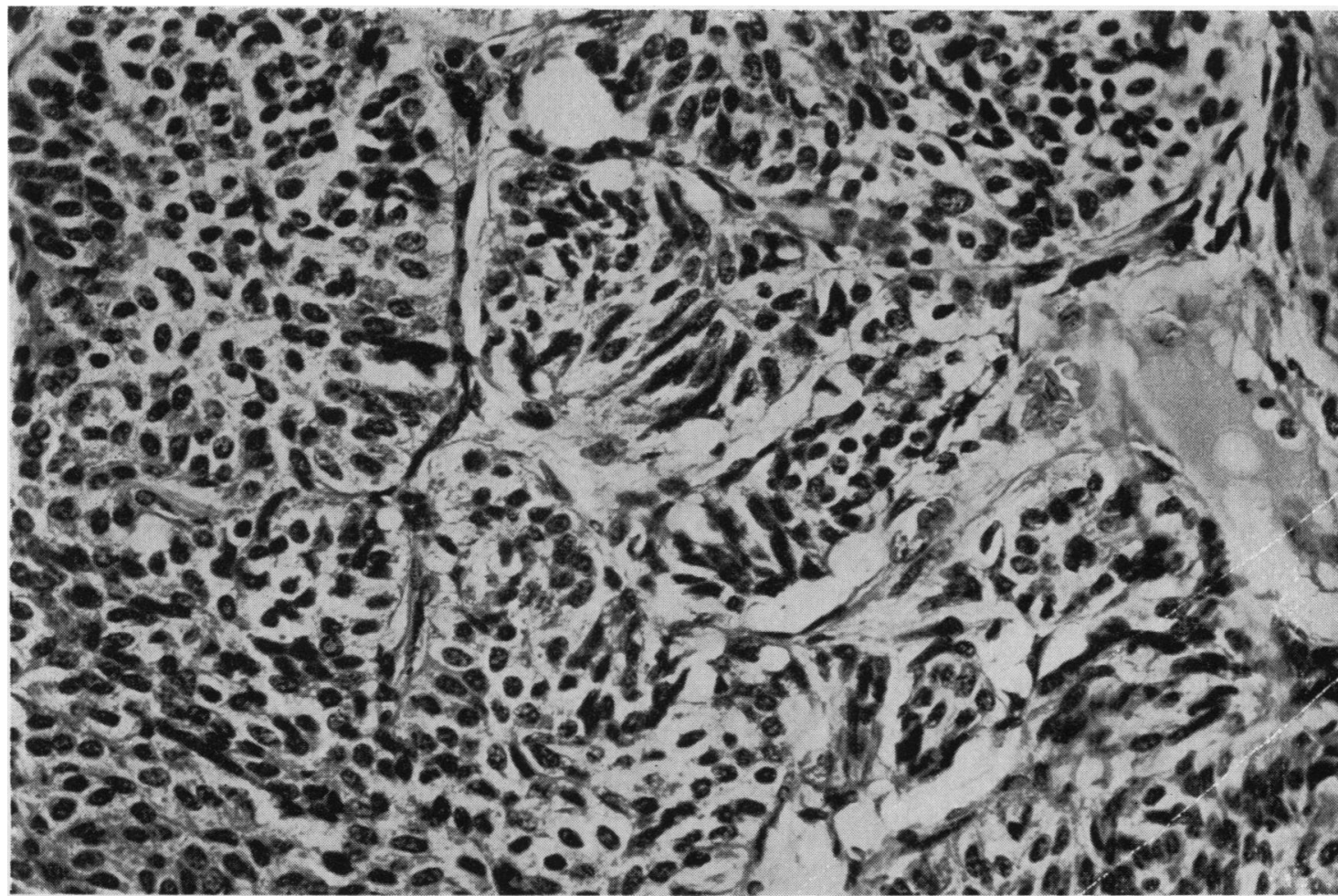

FIG. 1.-Typical tumourlet showing groups of cells with dark-staining nuclei and pale cytoplasm. The cells are regular and no mitoses are evident. $(\times 350$.)

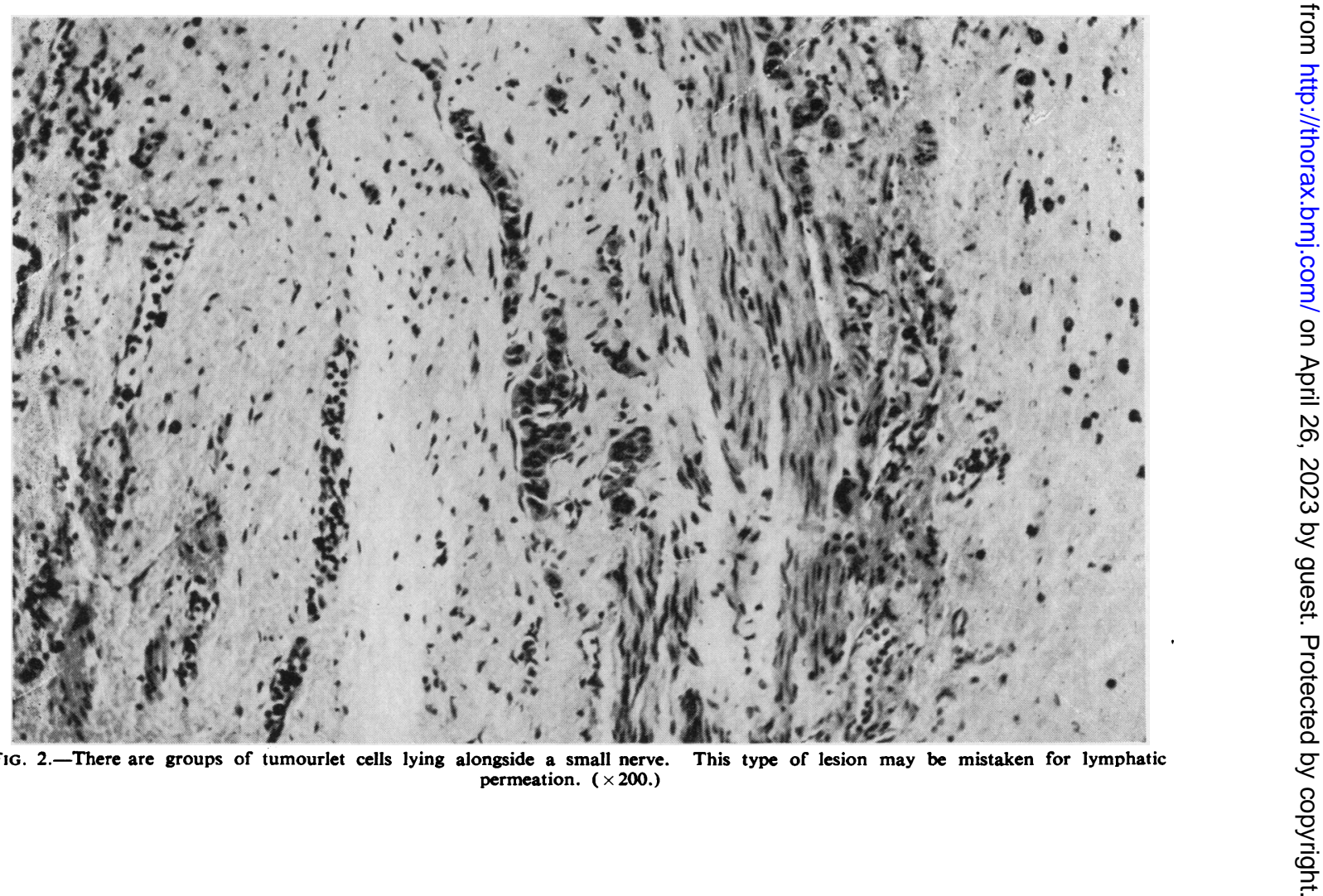


and under, only three out of 49 had tumourlets. Tumourlets were found in $17(32.1 \%)$ of the 53 patients aged more than 20 years. Eight $(26.6 \%)$ of 30 specimens from males and nine $(39.1 \%)$ of 23 from females contained tumourlets.

In 11 cases two separate lobes or parts of lobes were available for examination from the same case. Tumourlets were found to be present in both lobes in four cases.

The size and number of tumourlets found are shown in Table $\mathrm{I}$. The size of the lesions was arbitrarily judged in comparison with the lowpower field using $\times 8$ objectives. In general it was found that the larger tumourlets tended to be more frequent in females and the smaller lesions were not only more frequent but more widely distributed in that sex.

In all those cases in which tumourlets were found the lymph nodes were examined and no secondary deposits identified.
Discussion

Although the nature of tumourlets is not undero stood, we would agree with Whitwell (1955) i stating that they are unrelated to bronchial car $\stackrel{\overline{\underline{\omega}}}{=}$ cinoma. Although many small or early lesion $\$$ may be found in a bronchiectatic lung, it is remarkable that they never attain any large size The largest which was found in this series measured $3 \mathrm{~mm}$. in its longest diameter, and therE is no evidence that these lesions ever progress te anything larger. The appearance of invasion wit cells invading lymphatic spaces may well be due to epithelial cells being trapped in fibrous tissue and attempting to regenerate the destroyed lung That regeneration in lung is possible in animals has been demonstrated by Montgomery (1944). and there is no reason why a similar process should not occur in man. The absence of lyme phatic metastases in our cases further supports this view, although two cases with deposits itb regional glands are reported in the literatures

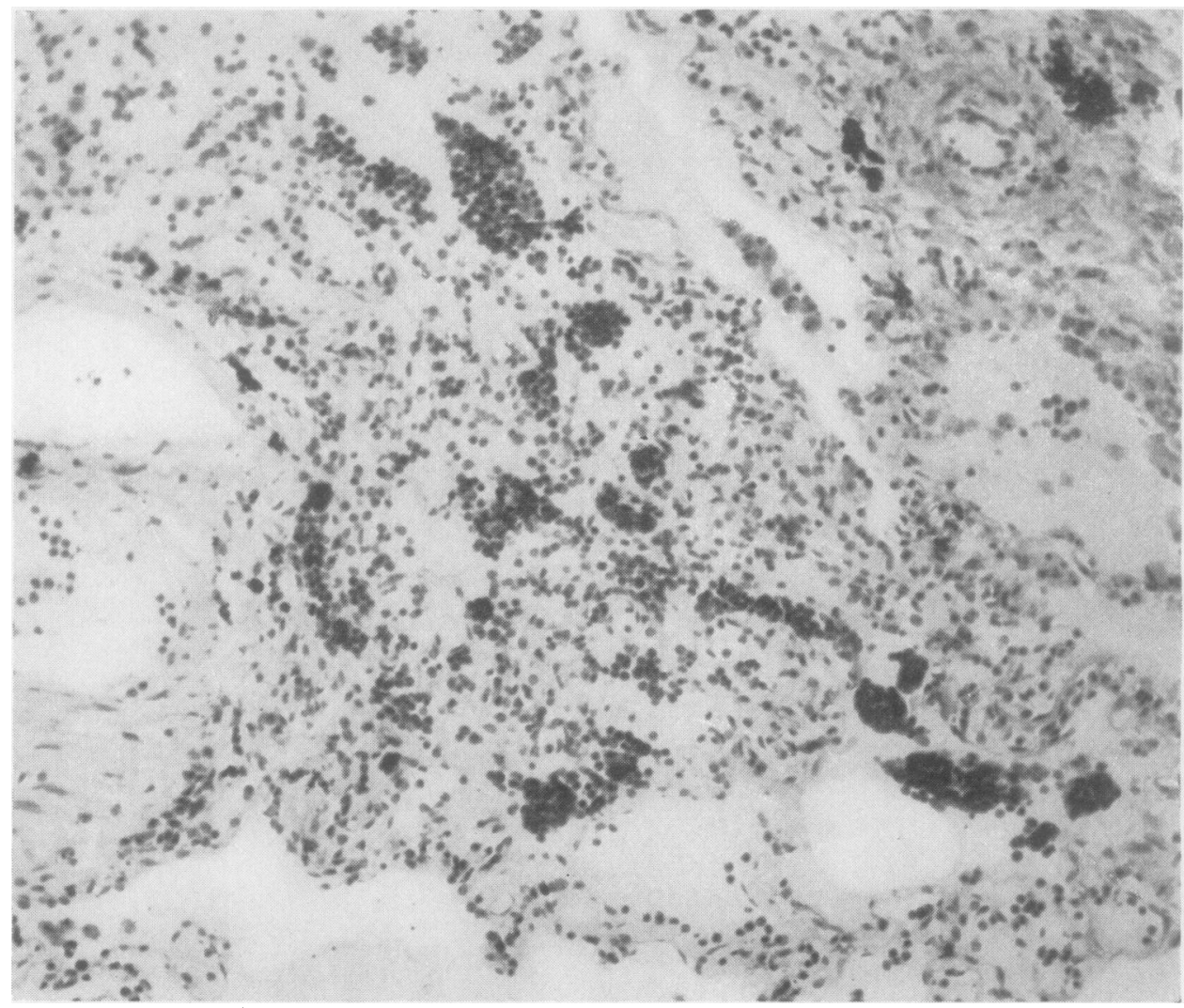

FIG. 3.-This field was adjacent to a tumourlet. The cells are small, with deeply staining nuclei, and are lying free in the alveoli. $(\times 160$. 


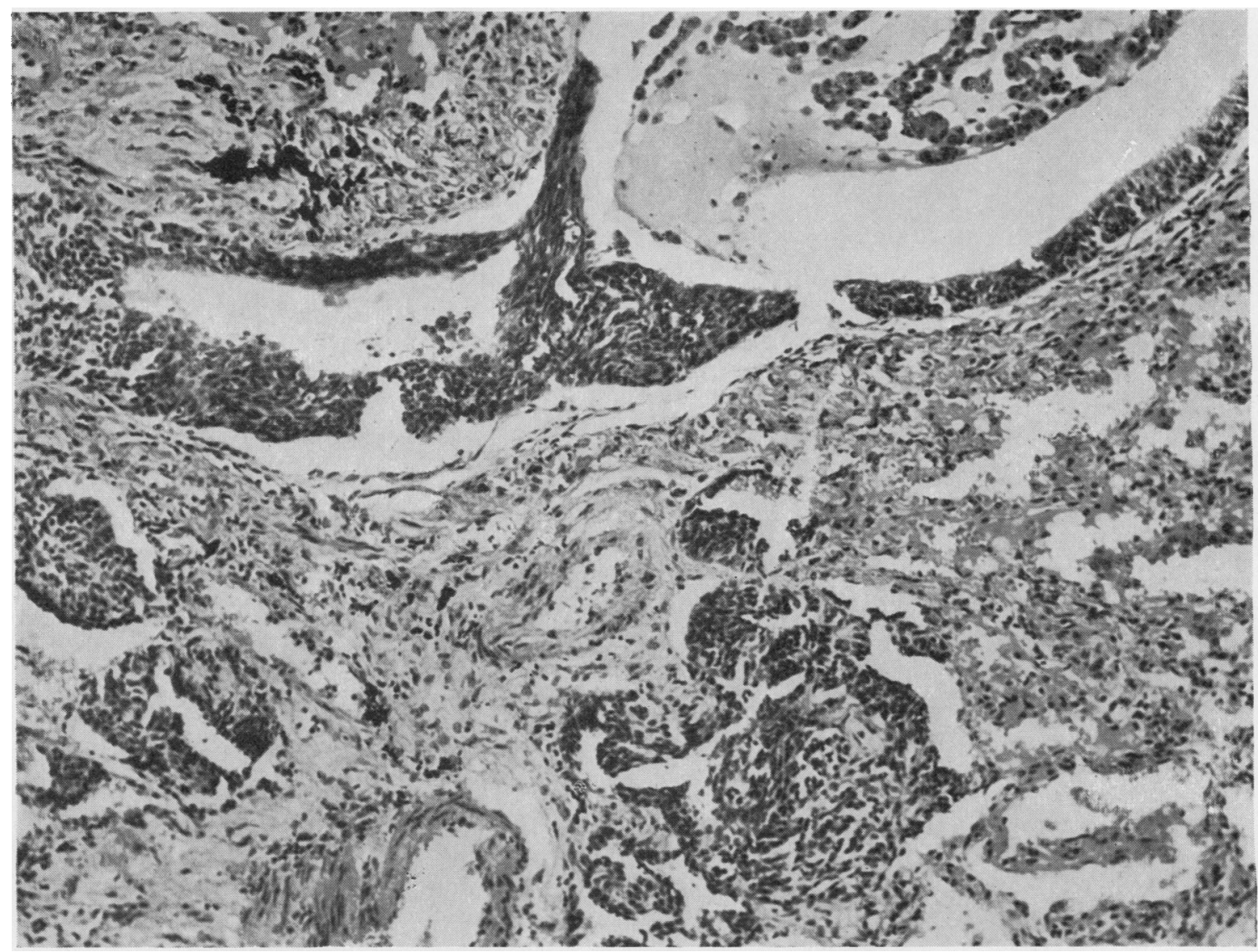

FIG. 4. - The tumourlet cells appear to be arising from the bronchiolar epithelium. $(\times 155$.

(Cureton and Hill, 1955; Spain and Parsonnet, 1951). The multicentric origin of tumourlets is further evidence against their relationship to carcinoma, since most carcinomata appear to start in one localized area of normal lung. The fact that in four of the cases in which two lobes were available for examination showed tumourlets in both specimens suggests than in any particular case these lesions are likely to be found in any of the affected lung tissue. Were these lesions premalignant, one would expect a high incidence of carcinoma in bronchiectasis even after local resections. In those series in which cases have been followed up (Whitwell, 1955), no such association between bronchiectasis and carcinoma has been found.

In our series the proportion of tumourlets found in men is much higher than that usually reported. However, we found that tumourlets tended to be larger and more numerous in women and therefore more likely to be found by chance sectioning.
This is probably the explanation of the higher incidence in females in previous reports. Previously no lesions have been reported in young people, the youngest apparently being one described by Whitwell aged 18 . In our series the youngest was 6 years.

The tumourlets were always present in damaged lung, and although large sections were used it was found that the lesions were grouped round the most severely damaged part of the lung (Fig. 6). The labour involved in preparing these sections is therefore unnecessary provided suitable small blocks are selected.

The frequency of tumourlets in bronchiectatic lungs $(39.1 \%$ in women over 20 and $26.6 \%$ in men over 20) appears to be of no clinical importance, but their finding by the pathologist is liable to be misinterpreted as evidence of carcinoma, and much needless anxiety may be occasioned to both the clinician and the patient. For this reason we think that these findings are worthy of report. 


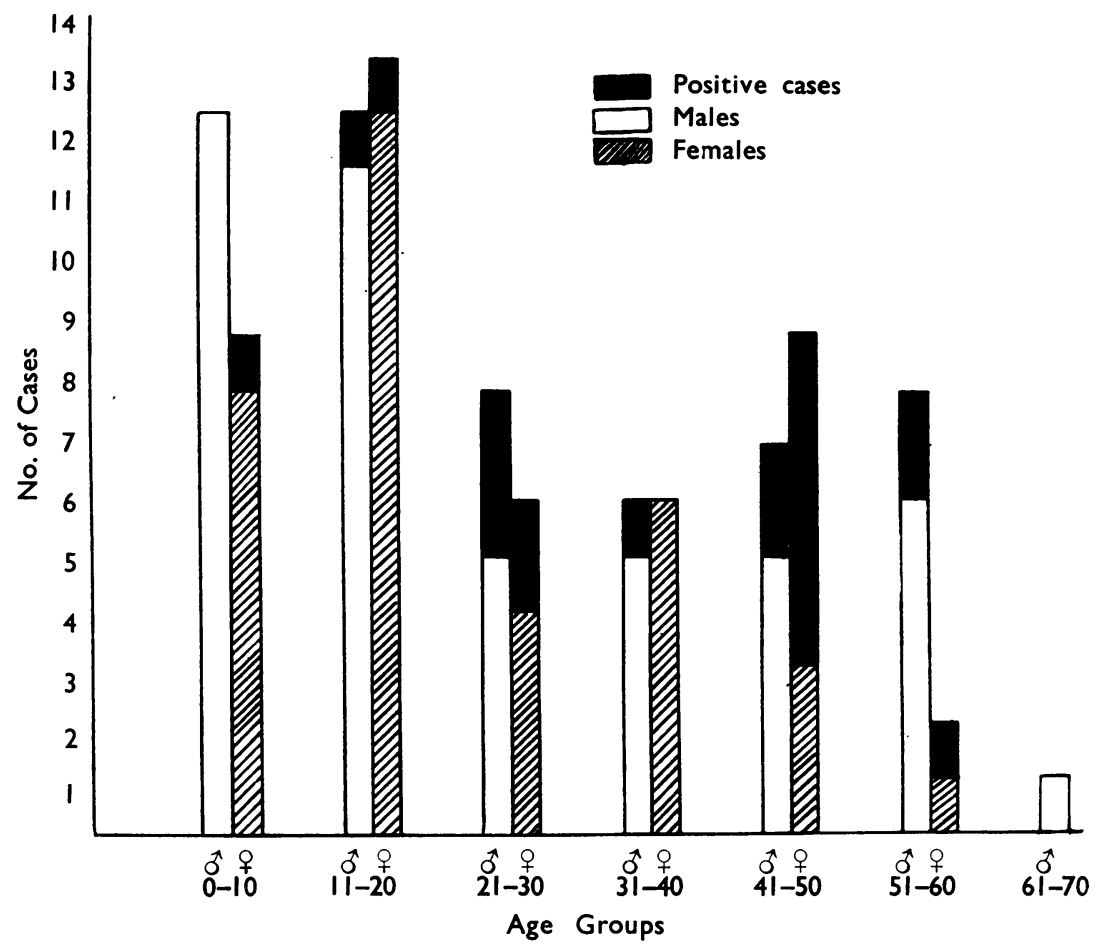

FIG. 5.-Histogram showing age and sex distribution of tumourlets.

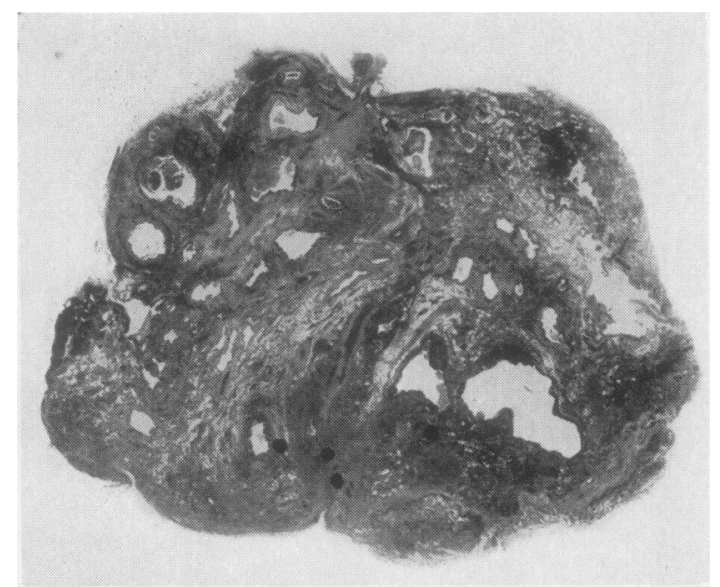

FIG. 6.-Section of whole lobe of lung (actual size) showing the site of four tumourlets. Note that they are situated in the most solid part of the lung.

\section{SUMMARY}

One hundred and two resected specimens of bronchiectasis have been carefully examined for tumour-like clumps of abnormal epithelial cells. These have been found in 20 . The youngest patient in whom such a "tumourlet" was found was a girl aged 6 , but the incidence was higher in adults than in children. Of specimens from patients above the age of $20,26.6 \%$ from men and $39.1 \%$ from women contained tumourlets. In women the tumourlets tended to be more numerous and larger, and it is suggested that this accounts for the previous reports of their greater frequency in women. The authors support the view that these lesions are not related to carcinoma though they are liable to cause difficulty in pathological diagnosis.

Our thanks are due to the Imperial Cancer Re- $N$ search Fund for a grant to study lung tumours, to the medical staff at Harefield Hospital, and, in particular, to $\mathrm{Mr}$. T. Holmes Sellors, for co-operation. We wish $\mathrm{\omega}$ to thank Mr. E. W. Spice, Mr. E. V. Willmott, and Mr. R. Chambers for photographic assistance.

\section{REFERENCES}

Bert, P., and Fischer, B. (1910). Frankfurt. Z. Path., 6, 27 Cureton, R. J. R., and Hill, I. M. (1955). Thorax, 10, 131. Montgomery, G. L. (1944). Brit. J. Surg., 31, 292.

Pagel, W. (1926). Virchows Arch. path. Anat., 262, 583. Spain, D. M., and Parsonnet, V. (1951). Cancer, 4, 277. Whitwell, F. (1955). J. Path. Bact., 70, 529. 